\title{
Psychological and pedagogical aspects of the development of engineering competencies of students
}

\author{
Besarion Meskhi ${ }^{1}$, Pavel Gerasin ${ }^{1}$, and Nadezhda Efremova ${ }^{1, *}$ \\ ${ }^{1}$ Don State Technical University, 1 Gagarin Square, Rostov-on-Don, 344003, Russia
}

\begin{abstract}
This article provides a brief analysis of the most demanded engineering competencies, it is shown that in the sum of educational results it is necessary to ensure a reasonable ratio of knowledge, competencies, and skills, since all of them to one degree or another ensure the success of engineering activities. The definitions of competencies and skills are given, the main problems of competence-based training are listed and possible ways to solve them are shown. The emphasis in the development of competencies is placed on the organization of project activities of students in groups. At the same time, it is important to ensure the planned student activity and the assessment of its individual types. An example of criteria for assessing various types of student activities in a situation of assessment is given, special attention is paid to operationalization and planning of assessment stages. An example of a level scale is shown, which allows using the aggregate of points for various types of activity to assess the level of competence formation based on the results of the task.
\end{abstract}

\section{Introduction}

The art of teaching, introduced by Jan Amos Comenius in his famous book "The Great Didactics" (1657), has laid the foundation for the development of the classroom system, in which the results of education were knowledge, skills and abilities. This universal holistic theory of training and education set the task in the years of adolescence to learn everything that is needed for present and future life [1]. For more than three hundred years, scientists and practitioners from different countries have developed techniques and teaching methods on this basis. And now, in the modern era, the "information explosion" and the permanent renewal of the technosphere, the rapid changes in society make such demands on education that the classical teaching theory does not provide this demand and is undergoing an acute crisis. New results are on the agenda in terms of competencies and skills of the 21st century, which should ensure the success of young professionals in an environment of uncertainty and constant change.

In many studies, the terms "competence" and "skills" are used interchangeably [2, 3]. From our point of view, these concepts have a clear difference. We understand competences as the ability to create and use new tools and techniques necessary for productive solution of

* Corresponding author: nefremova61@donstu.ru 
problem situations based on reflective analysis and overcoming deficiencies in the field of professional activity. In contrast, skills are persistent, repetitive methods of activity. Both those and other qualities are necessary in order to act and successfully solve emerging problems, especially in engineering.

The training of engineering personnel requires special attention in connection with the cardinal changes in the technology of engineering labor. In the context of new socioeconomic relations and the intensive development of the information space, it is absolutely impossible to predict the required "graduate model" even for 3-5 years (at the end of the training cycle). Therefore, determining what a graduate of a high school should be prepared for is a big problem. At the same time, the education system must prepare young people for such living conditions that no one can yet know about. Therefore, it becomes necessary to obtain results based on fundamental knowledge, hands-on experience and the ability to apply knowledge to solve socially and professionally significant problems. It is believed that a set of important competencies will help a person adapt in a constantly changing world and large flows of information, navigate and learn throughout life, and be successful in work.

Knowledge production is becoming a leading factor in economic growth. Therefore, new engineering thinking and the importance of engineering competencies cannot be overestimated. Many global companies are looking for ways to overcome the shortage of highly qualified engineers by creating corporate universities, designing short-term programs of additional education and retraining, actively participating in the formation of the competence profile of a demanded specialist. Information about the demanded competencies of an engineer is constantly updated and supplemented by the results of surveys of various categories of employers and researchers $[4,5]$.

Most national and global research provide requirements for specialists and justify models of the required competencies. For instance, the American model of an engineer is focused on possessing broad and deep fundamental knowledge and the ability to use it as the basis for practical engineering; analysis of engineering problems, design and development of engineering solutions [6]. Attempts to create promising models of engineering competencies and study the future demand for them have been and are being made in a number of largescale initiatives of the European Commission and OECD [7, 8]. Responsibility for engineering decisions, ethics and safety of engineering actions (understanding the social, cultural and environmental consequences of integrated engineering actions, including with respect to sustainable development) is noted. A more detailed description of the complex engineering activity and the requirements for the professional competencies of engineers and university graduates are set out in the founding IEA Graduate Attributes and Professional Competences [9] document. The Association for Engineering Education of Russia (AEER) identifies fundamental knowledge in a broad context in complex engineering activities as the most important characteristics: engineering analysis and engineering design; integrated engineering research and engineering practice [10].

Most of the studies focus on the use of theoretical knowledge, engineering invention, productive teamwork, communication in native and foreign languages on professional topics, the ability to express thoughts in an accessible way, the rapid assimilation and application of new knowledge, analytical skills, stress resistance, the ability to critically assess our own and others ideas, high ethical standards, commitment to continuous development. However, there are few works that reveal how to ensure the formation, development and assessment of these characteristics in the educational activities of a technical university. The existing deficit of scientific research in the field of formation and assessment of competencies is partly due to their latency and complexity, the interdisciplinary nature and variety of learning models, and the specificity of manifestation only in activities. In the context of a differentiated system of higher education, the assessment of students' competencies is a major methodological problem. 
The relevance of this study is precisely due to the need to develop a technology for the development of competencies in the context of ensuring the planned activities of students in the learning process.

\section{Problems of competence learning}

A historical review of the literature shows that approaches to the formation of competencies at the national and institutional level have been undertaken for over 25 years. A brief analysis of the requirements for modern engineering activities indicates the complexity of training young specialists to work in this area. Recently, the technology of competence-based training has become leading in achieving the required quality of education, which brings into line, on the one hand, the individual's needs to integrate himself into the activities of society and, on the other, the country's need to effectively use the potential of each individual for economic, cultural and political self-development. However, a thorough review of the literature allows us to come to the understanding that competence-based education is not yet a clearly packaged model of training specialists, and learning outcomes still do not always occupy a central place in the education system. The application of the European system of accumulation of credits and transfers (ECTS) in domestic education is not consistent either within the educational institutions themselves, or between them. In addition, the collection of institutional, national and regional data that could be used to assess the effectiveness of reforms and plan improvements, such as degree portability, employment, retention and completion rates, teacher-to-student ratio, and socioeconomic demographics, remain problematic in world educational practice [11, 12].

The problem lies in the fact that the results of competence-based learning differ significantly from traditional (cognitive) ones both in the technologies of their formation, and in the means and methods of assessment [13]. As a result of the formation of competencies, they have a very complex component composition (clusters, profiles, levels), are formed on an interdisciplinary basis, they are deeply latent in nature and are very difficult to manifest, therefore they are difficult to form, identify and evaluate. At the same time, it should be noted that the formation of competencies and skills of the XXI century is not a substitute for mastering the content of academic disciplines, but is considered as an important and necessary addition to them, providing the ability to effectively apply knowledge and act effectively in the modern world.

In these conditions, pedagogical activity becomes more and more complex and multifaceted, responsibility for learning outcomes and, what is important, for their reliable assessment increases. In order to achieve the planned results of competence-based training, teachers need to design, create and use an appropriate educational environment in which students can learn, develop and act. A number of questions arise before teachers. What competencies to form and how to form them? What educational technologies to use? How and at what stages of training to assess the levels of competencies? What form of assessment of achievements in the development of competencies to offer during training and at the final certification? To answer these questions, a modern teacher himself must possess many competencies in order to skillfully use them and contribute to the development of students.

\section{Technology of project training}

To ensure the conditions for the development of competencies in the training of specialists in the field of engineering, we used the project teaching method as a leader, which ensures the work of students in a team when solving complex interdisciplinary tasks. 
As an example, consider the RapidFarm training module for first-year students of the Institute of Emerging Technologies "School X" of the Don State Technical University.

The purpose of the module is to familiarize students with the smart agriculture industry, create conditions for conscious self-determination and further choice of a professional track, as well as design and implementation of an integrated engineering solution for designing an automated greenhouse for growing vegetables or microgreens. The module is implemented within two months and includes the acquisition and application of knowledge from various fields: biology and chemistry (plant physiology and management of their properties, nutrient solutions, city farming); design (computer-aided design systems, construction of lightweight structures and greenhouses, additive technologies); robotics (automation, sensors); information technology (programming, internet of things); economy.

Students are assigned 8 people in each team to work on a project. They should: conduct a market analysis of smart agriculture; assess the prospects for its development in the world and in Russia; highlight the problem for the formation of the project; formulate the purpose of the project (optional - to find a specific customer for the designed engineering solution); assign roles in the team and draw up a work plan; execute scheduled tasks, synchronizing results within the team; assemble a prototype of an engineering solution and prepare a project presentation in Russian and English. When designing this module, a systematic approach was used, students should examine the problem from all perspectives and offer not just a set of individual ideas or proposals as a solution, but a finished complex product, including a justification of technological, economic, environmental contexts that may be in demand on the market.

The training module is divided into four stages:

- introductory provides immersion in the topic and substantiation of the relevance of the task, is implemented in the form of a short design and analytical session, which is an important part of the module, because it is at this moment that students are motivated for further work; - work on the project includes, in addition to teamwork, gaining knowledge from relevant areas related to the design of automated greenhouses, an excursion to the greenhouse complex to get acquainted with real production and the opportunity to ask questions to employees;

- preparation of a presentation and demonstration of a prototype of an engineering solution, defense of a project to experts;

- conclusion and results, including providing feedback, reflection, self-assessment and peer review.

During the implementation of the project, the emphasis is placed on the development of such competencies as problemization, work with information, communication.

To achieve the set goals, the following conditions were created: preparation of students for understanding by all participants the goals and objectives of the module; providing the opportunity for students to work together in teams; coordination of the cognitive and competence components of training (disciplinary binding and planned activities) with design tasks; creation of a physical prototype for obtaining the necessary skills and abilities.

Based on the results of mastering the training module, the team must submit: a prototype of an engineering solution in accordance with the terms of reference; presentation with the main results achieved by the team during the design; video presentation of the project in English. Oral presentation of the results is submitted to the defense and evaluated with the obligatory participation of experts from the relevant industry.

After discussing the projects, additional positions were introduced into the educational process to ensure the effective fulfillment of the above conditions.

The owner of the module (module leader) ensures the construction of the module, evaluates the progress of the teams during its implementation, advises students and coordinates the work of engineering mentors and team moderators, is responsible for the final result of the implementation of the module. 
The engineering mentor of the team advises on technical issues, helps to understand issues related to creating a physical prototype, using tools and materials, and finding the necessary information.

The team moderator monitors compliance with the project protocol, provides conditions for the team's activities from analyzing the situation through problem-setting and goal-setting to designing a specific engineering solution.

The position of an engineering mentor or team moderator can be occupied by senior students with the appropriate competencies and a desire to occupy this position. They, according to predetermined criteria, can evaluate the activities of students in a group during the implementation of a project.

\section{Competencies assessment techniques}

Recently, at all levels of education, considerable attention has been paid to assessing the educational achievements of students. The demand for authentic results of education determines the formation of an international educational space, digitalization processes, new requirements of employers and, as a consequence, a change in the educational paradigm, which led to the transition from a knowledge-based approach to competence-based learning. In addition, the relevance of new educational standards provides for an increase in the time for independent work of students. These and other events have changed the approach to assessing educational achievements and identified the problem of ensuring its reliability. At the same time, both in domestic and foreign education, there are a number of problems with ensuring reliable assessment of educational achievements. This is primarily due to the unpreparedness of the teaching staff to develop and apply standardized assessment tools and assessment mechanisms in accordance with statistically sound criteria for achieving the planned results. And this is especially difficult in terms of assessing the formation of competencies and skills of the XXI century. To provide a basis for student confidence in learning outcomes, it is necessary to develop and use reliable and valid grading tools to produce authentic grades.

In the world educational practice, the approach to assessment is based on the use of sound standards and criteria, which allows to guide educational activities and support effective learning, to fairly measure academic performance according to the degree of achievement of the planned results by students, to determine and maintain academic standards [14]. An approach to assessment based on standards and criteria allows students to understand the requirements for mastering disciplines and practices, to know at what stage of learning how achievements will be assessed. This ensures the credibility of the assessment process and creates conditions for the legitimacy of judgments about performance. J. Biggs (2003) believes that in order to get high marks, students must know the goals and learn to achieve them [15]. And they understand goals most clearly when they are informed about the requirements for learning outcomes and assessment, how the results of the assessment tasks will be assessed. Therefore, for an assessment to be considered valid, it requires a clear alignment between the intended learning outcomes, learning activities, and the assessment methods and objectives used to measure achievement of those outcomes. A standards and criteria-based approach ensures the reliability of the assessment, articulates the teacher's and student's expectations of what should be achieved, creates the conditions for the transparency of the assessment and a common understanding of the goals and learning outcomes. Competence-based training can be viewed as a form based on continuous analysis of the results of an authentic assessment of student achievement. Assessment as a process of establishing a value relationship to the state of an object, analysis and search for opportunities to improve achievements. 
The standards set the process of regulating the assessment process from the development of control and measuring materials to the receipt and analysis of results, describe the level or quality of educational achievements of students in the assessment task. Standardization ensures the unity of requirements and is the basis for ensuring an objective assessment of the compliance of educational activities achieved with the established requirements and training of students at a particular level of mastering disciplines and practices. And, it is important that it ensures comparability of results, allows for comparative analysis and to see the positive aspects of the educational process and its shortcomings. Assessment standards can take various forms, but, as a rule, they contain concise but sufficient information about the quality and level of student achievement, the content and form of assignments, the requirements for their implementation and the conditions for assessment. In turn, the criteria determine the key characteristics or attributes of student performance in the assessment task, what should be present in the student's efforts during the assignment, and what the student should demonstrate to identify learning outcomes. Teachers who strive to ensure objectivity and reliability in the assessment of learning outcomes are required to develop standards and criteria for assessment tasks within their disciplines and at the interdisciplinary level. This will make it possible to make reliable and reasonable judgments about the quality of assignments to assess the planned learning outcomes.

One of the successful attempts at the federal level was the development of a personnel testing standard [16]. It sets out the requirements for the main stages of preparation and conduct of this kind of assessment process. Particular attention is paid to testing methods, requirements for the reliability and validity of materials, data processing and interpretation, and the interconnection of test results with the results of other assessment procedures, as well as ethical standards during assessment. Many principles and provisions of such an assessment process can be used by teachers to develop their own standards, criteria and organization of assessment procedures.

The lack of valid tools and methods for assessing competencies in the education system limits the degree of development and the possibility of operationalizing competence-based approaches to learning. First of all, today there is an acute problem of proper professional training of teachers, the development of assessment tools to identify and determine the levels of competence formation, the principles of selection and development of tools and assessment mechanisms. Assuming that teachers are not sufficiently trained in developing assessments with the required level of rigor and consistency, it is necessary to create samples (reusable template models) of modern assessment tools to effectively demonstrate the declared competencies by students in the assessment situation. Targeted faculty development activities are needed to help educators make sense of the cumulative results of the assessment and use the lessons learned to improve performance.

The key task is to provide stakeholders in the educational process, including students, with reliable information about the overall picture of assessment and the principles of combining its elements into the final result. Central to this task is reaching agreement on a semantic model for assessment (fig. 1.). 


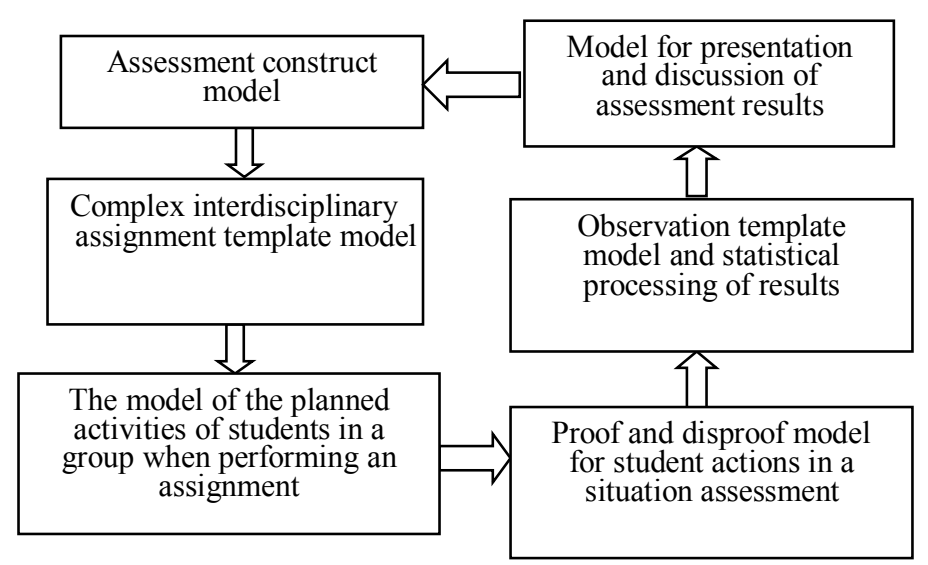

Fig. 1. Assessment modelling.

Assessments of skills and competencies, combined with the results of mastering the content of academic disciplines, affect the processes of improving educational programs, methods and technologies of teaching and learning, directing them to the development and effective use of solving educational and professional problems. Many countries practice the use of complex, interdisciplinary approaches to assess competencies and skills. Assessment materials include not only analytical elements of answers to the assessment of knowledge, but also complex competence-oriented tasks that require students to analyze and make more extensive use of educational information obtained in the learning process or found in various sources. When solving tasks, the answers are practiced both orally and in writing. As the learner moves from knowledge to demonstrating skills and competencies, values and attitudes, they move closer to mastering the principles of creativity, innovation and ways of working. These transferable learning outcomes are usually shaped by different disciplines and are assessed by completing assignments built on interdisciplinary content. To increase the reliability of the assessment of skills and competencies, their observation and assessment should be carried out for a sufficiently long time and in the context of taking into account the conditions of their formation.

An important step in the design of assessment is the operationalization of cognitive and competency learning outcomes for inclusion in the construct model (fig. 2). 


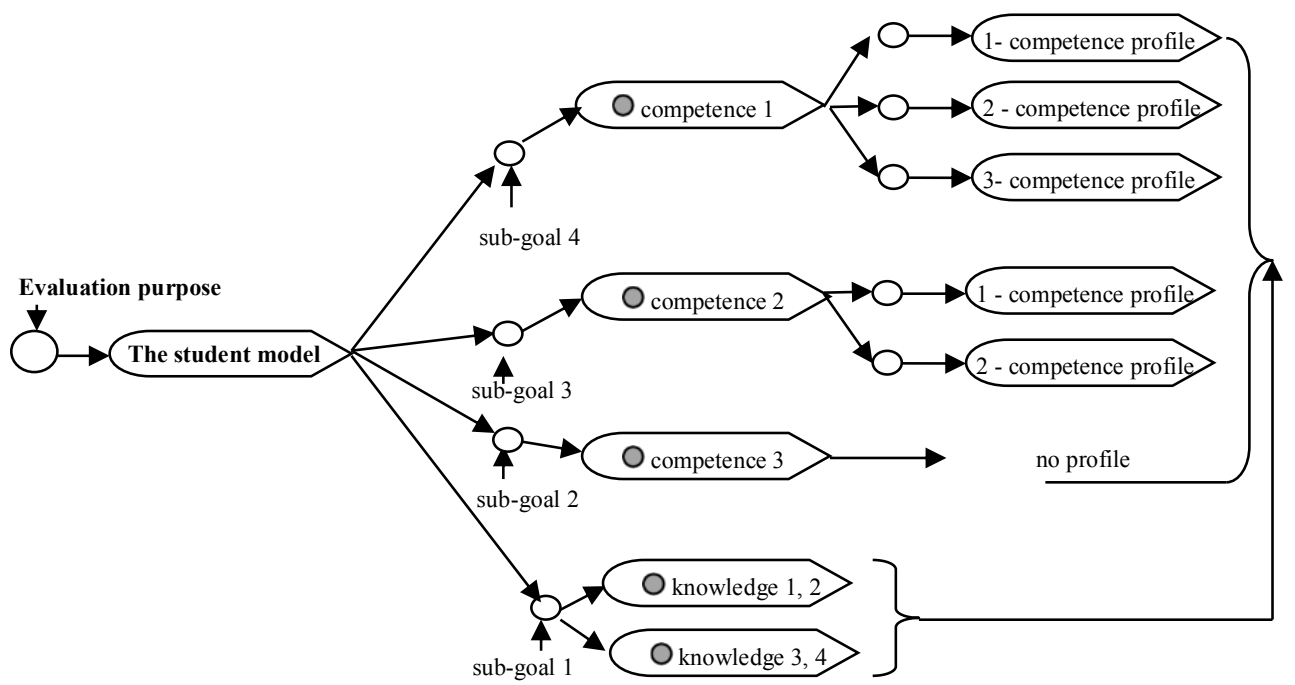

Fig. 2. Multidimensional Assessment Construct Model [17].

The results of the assignment are evaluated according to the criteria for each planned student action in the assessment situation. The total of the points received is displayed on a level scale (fig. 3).

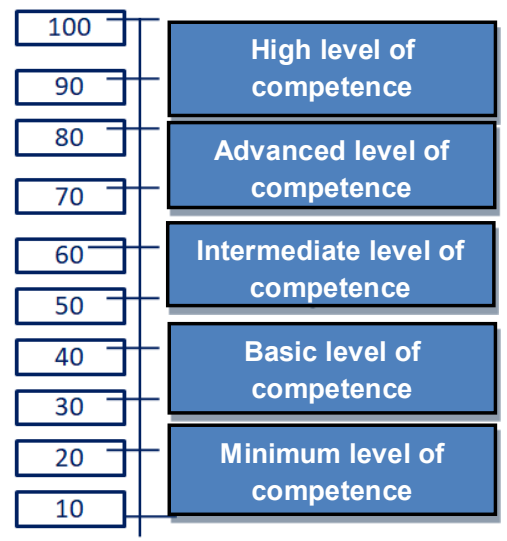

Fig. 3. Level scale for assessing competencies.

It can be either cumulative in points for completing the elements of the task $=\mathrm{K}_{1}+\mathrm{K}_{2}+$ $\ldots+K_{n}$, where $K_{i}$ is the score for the $i$-th criterion, or penalty $=S_{\max }-P_{1}-P_{2}-\ldots-P_{n}$, where $\mathrm{S}_{\max }$ is the maximum score for correct the task is completed, and $\mathrm{P}_{\mathrm{i}}$ is the penalty for the $\mathrm{i}$-th criterion. The number of levels and their range are set by the teacher, based on the goals and objectives of the assessment process. The tiered approach does not provide for comparing the achievements of students with each other, it is the basis for organizing individual work.

Authentic assessment of skills and competencies can serve the main purposes: to expand knowledge about various approaches to the integration of information flows for their use in solving problems; provide information on how learning is progressing within the educational system. By type of assessment, they are divided into formative (current) and summative (final). The first are aimed at diagnosing and monitoring achievements in order to improve the learning and development of students, and influence the motivational sphere. The latter 
allow making decisions about the level of mastering disciplines and practices. Various methods and techniques of assessment activities should be strategically combined into a holistic consistent assessment program [18]. For each competence, it is important to determine the means and methods of assessment that give a set of multidimensional results that ensure their reliability and validity; the rules for determining criterion points and weight coefficients for the integration of multidimensional assessments are set; recommendations for the interpretation and presentation of the results to interested parties were developed.

\section{Conclusion}

The transition to competence technologies and teaching methods is inevitable. It is already widely used in some of the world's leading universities [19-21], and is gradually beginning to enter the educational practice of Russian education $[22,23]$. It is very important to note that the competence-based approach should not conflict with the cognitive (traditional) one. The importance of knowledge, skills and abilities has been, is and will be the basis of quality education. At the same time, traditional technologies must be complemented by new forms of active learning. Without knowledge and skills, competencies are not formed, but, in turn, without competencies, knowledge does not manifest itself and cannot be used for productive activity. Therefore, only a reasonable combination of cognitive and competence-based results can provide effective engineering activities for graduates. Today, the task is to develop such a teaching methodology in which both types of results can be formed and mutually complemented in the learning process, which provides for the productive activity of students.

A number of aspects can be noted in the technology of competence learning:

- high motivation for educational activities should be provided based on the selection of interesting situations for the organization of project activities of students;

- the formation of an integral scientific view of the world can be formed only on the basis of mastering the fundamental knowledge;

- for the development of competencies, it is necessary to use various forms of group and individual work, in which the individual achievements of the student must be combined with an orientation towards the final result of the group;

- for organizing the project activities of students, it is important to use complex tasks with sets of practice-oriented tasks built on interdisciplinary content;

- a component of competence-based training is a systematic control and assessment activity, which is built in the interests of students on the principles of self- and mutual assessment, expert intermediate and final assessment, followed by reflection on achievements and problems.

Given the growing internationalization, it is important to take into account international experience when developing and assessing competencies, ensuring the reliability of assessing students' knowledge and competencies in various learning models, ways to ensure transparency of the levels of educational achievements of students in different countries.

\section{References}

1. J. Amos, Comenius, The great didactic (2013)

2. S. Gerasimov, Engineering education 6, 18-25 (2010)

3. K. Ford, Competency-Based Education: History, Opportunities, and Challenges (2014) doi: 10.13140/RG.2.1.4679.0885

4. C.-G. Kuo, C.-C. Chang, International Journal of Photoenergy 40, 1-6 (2014) doi: $10.1155 / 2014 / 963291$ 
5. S. Blömeke, O. Zlatkin-Troitschanskaia, C. Kuhn, J. Fege, Modeling and Measuring Competencies in Higher Education (2013)

6. A. Chuchalin, Educational Studies Moscow 1, 84-94 (2007)

7. N. Shmatko, Foresight 6, 32-47 (2012)

8. D. Denchuk, O. Zamyatina, M. Minin, V. Sadchenko, Modern problems of science and education 6, 934 (2014)

9. International Engineering Alliance, Graduate Attributes and Professional Competencies (2013)

URL: https://www.ieagreements.org/assets/Uploads/Documents/Policy/Graduate-Attributesand-Professional-Competencies.pdf (Last accessed 2021/02/22)

10. S. Gerasimov, E. Yatkina, Engineering education 7, 58-67 (2011)

11. A. Sursock, H. Smidt, Trends 2010: A Decade of Change in European Higher Education (2010)

12. A. Sursock, Trends 2015: Learning and Teaching in European Universities (2015)

13. N. Efremova, Modern Scientific Technologies 7, 169-174 (2019) doi 10.17513/snt.37607

14. S. Armstrong, S. Chan, J. Malfroy, R. Thomson, Assessment Guide. Implementing criteria and standards-based assessment (2015)

15. J. Biggs, Teaching for Quality Learning at University (2003)

16. Russian personnel testing standard, Organizational Psychology 5, 67-138 (2015)

17. N. Efremova, Pedagogical measurements 3, 8-15 (2018)

18. N. Efremova, O. Shapovalova, A. Huseynova, E3S Web of Conferences 210, 1-7 (2020) doi: $10.1051 / \mathrm{e} 3$ sconf $/ 202021018021$

19. M. Sencer Corlu, K. Svidt, D. Gnaur, R. Lavi, Cognition, Metacognition, and Culture in STEM Education 241-259 (2018) doi: 10.1007/978-3-319-66659-4_11

20. A. R. Carberry, D. R. Baker, Cognition, Metacognition, and Culture in STEM Education, 217-239 (2018)

21. H. Smidt, A. Sursock, Engaging in Lifelong Learning: Shaping Inclusive and Responsive University Strategies (2011)

22. A. Shcherbakova, A. Soyunov, Electronic Scientific And Methodological Journal Of Omsk SAU 3(10), 26 (2017)

23. O. Ulyanina, Psychological And Pedagogical Research 10, 135-147 (2018) doi: 10.17759/psyedu.2018100212 